\title{
ASSISTÊNCIA À GESTANTE HIV + NA PERSPECTIVA MULTIPROFISSIONAL EM SAÚDE
}

\author{
Luana Gabriella Pinheiro Barrêto ${ }^{1}$ \\ Zannety Conceição da Silva Nascimento Souza ${ }^{2}$
}

1. Voluntária PEVIC, Graduando em Enfermagem, Universidade Estadual de Feira de

Santana, e-mail: luanagpb10@outlook.com

2. Orientadora, Departamento de Saúde, Universidade Estadual de Feira de Santana, e-mail: zannetyenfermeira@gmail.com

PALAVRAS-CHAVE: HIV, Saúde da Mulher, Profissionais de Saúde.

\section{INTRODUÇÃO}

O Vírus da Imunodeficiência Humana (HIV) vem disseminando-se de forma gradual e intensa nos países subdesenvolvidos. No Brasil, essa infecção teve início na década de 1980. No início, a infecção se relacionava com pessoas do sexo masculino e homossexuais. Atualmente, vem atingindo mulheres de todos os níveis conjugais e sociais (BARROS et al., 2012).

No município de Feira de Santana, Bahia, segundo os dados do Departamento de DST, Aids e Hepatites Virais, o número de casos de HIV notificados no SINAN, do ano de 2010 até 2015, foi de 611, sendo 392 no sexo masculino e 219 no sexo feminino. A quantidade de gestantes portadoras de HIV foi de 65 , a taxa de detecção do vírus aumentou em quase $143 \%$ entre estas, neste mesmo período (BRASIL, 2016).

A escassez de dados sobre a assistência às gestantes HIV+ no Centro de Referência DST-HIV-AIDS do município de Feira de Santana - BA e a necessidade de ampliação do conhecimento sobre a atenção dispensada a essas mulheres foram justificativas para a realização deste estudo, bem como os benefícios que esta pesquisa poderá oferecer aos acadêmicos, profissionais da área e pessoas com o diagnóstico de $\mathrm{HIV+}$, ao elucidar o trabalho multiprofissional e respaldar a melhoria das práticas profissionais por meio das reflexões a partir dos resultados.

Assim, o objetivo deste trabalho é compreender a atuação dos profissionais de saúde na assistência às gestantes HIV+ no CTA de Feira de Santana - BA.

\section{MATERIAL E MÉTODOS}

A presente proposta de Iniciação Científica (IC) integrou o projeto, intitulado: "Atenção à Saúde da Mulher nos Serviços Públicos do Município de Feira de Santana - BA”, que tem por objetivo, analisar a atenção à saúde da mulher nos serviços públicos do município de Feira de Santana - BA, no ciclo gravídico puerperal, na saúde reprodutiva, no atendimento em ginecologia e nas situações de violência $\mathrm{O}$ mesmo foi aprovado pelo Comitê de Ética em Pesquisa com Seres Humanos da Universidade Estadual de Feira de Santana (CEP-UEFS), sobre o CAAE $\mathrm{n}^{\mathrm{o}}$ : 49615815.0.0000.0053, parecer de $\mathrm{n}^{\circ} 1.327 .867$ e autorizado pela Resolução CONSEPE $n^{\circ}$ - 008/2016.

Trata-se de um estudo Qualitativo, exploratório realizado no Centro de Referência DST - HIV - AIDS no município de Feira de Santana - BA, que é subdivido em três setores, o primeiro e principal porta de entrada do serviço, denominado Centro de Testagem e 
Aconselhamento - CTA, onde todos os pacientes passam pelo aconselhamento pré-teste e pósteste das DST's em geral; outro específico para o atendimento aos pacientes que possuam alguma DST exceto os que tiveram positividade para HIV; e por fim o Serviço de Atendimento Especializado - SAE, onde as pessoas diagnosticadas com HIV são acompanhadas.

Participaram 16 profissionais de saúde que atuavam diretamente na assistência às gestantes, sendo eles: médicos, enfermeiros, assistentes sociais, psicólogos, farmacêutico, técnicos de enfermagem e laboratório. A coleta de dados se deu por meio de entrevista semiestruturada após assinatura do Termo de Consentimento Livre e Esclarecido (TCLE); foi gravada em um local privativo na unidade e todos os dados coletados transcritos e armazenados, e posteriormente analisados. O método utilizado foi a Análise de Conteúdo de Bardin.

\section{RESULTADOS E DISCUSSÃO}

A atuação multiprofissional foi percebida nas falas dos entrevistados, o que nos leva a refletir que os próprios profissionais reconheceram a importância do trabalho em conjunto, para melhor atender as necessidades dos pacientes, o que também leva a uma valorização da área de conhecimento do outro. Os participantes relataram que conseguem resolver a maioria das demandas sem a necessidade de encaminhar a gestante para outra unidade, justamente pelo SAE contemplar ações profissionais diversas, dentro do mesmo espaço, o que facilita o fluxo e o acesso das mulheres.

Ao conversar com os participantes, independente da categoria profissional, foi comum o discurso de que a enfermeira é a responsável pelo primeiro contato com as gestantes HIV+e a partir deste acolhimento, inicia-se o fluxo da assistência multiprofissional. A enfermeira é responsável por receber essa gestante na unidade já no CTA, para a realização do rastreamento e do aconselhamento pré-teste e pós-teste, a solicitação dos exames - testagem para HIV e sífilis, bem como pela orientação sobre os mesmos, respeitando a prioridade desta no atendimento.

$\mathrm{O}$ atendimento realizado pela enfermeira no CTA difere do atendimento das enfermeiras do SAE. Neste último, elas fazem a admissão da gestante HIV+ já ciente do seu diagnóstico, fornecem orientações sobre o serviço e faz os encaminhamentos internos para a equipe multiprofissional, de acordo com as necessidades identificadas na abordagem inicial da admissão da usuária.

A enfermeira percebe a assistência à gestante HIV+ em sua integralidade, pois relata a parceria com outros profissionais na observação dos aspectos clínicos, laboratoriais e também psicológicos, já que a gestação altera os aspectos emocionais por si mesma, e associada à vivência do HIV, pode fragilizar a mulher, trazendo-lhe sentimento de medo e angústias, às vezes chegando a pensamentos auto-destrutivos.

Em relação ao atendimento médico, o serviço especializado possui especialidades como ginecologia e infectologia que trabalham em parceria no atendimento à gestante. Observou-se a partir das entrevistas que a atuação do profissional médico visa à redução do risco de transmissão vertical do vírus ao feto por meio de terapia medicamentosa pautada nos exames laboratoriais.

Notou-se ainda por parte da equipe médica a preocupação em orientar à gestante sobre a importância da adesão e fidelidade ao tratamento, bem como os cuidados gerais para a melhoria da qualidade de vida durante a gestação, mesmo convivendo com o vírus HIV. Uma das dúvidas das gestantes que é necessária intervenção médica é sobre a impossibilidade de amamentar e o uso de medicação para bloquear a produção do leite materno e o atendimento 
médico também inclui o acompanhamento pré-natal com a solicitação de exames de rotina para avaliação da saúde geral da gestante e do feto.

Porém, algo do trabalho do médico chamou a atenção em uma entrevista, pois foi relatado que seria papel deste notificar quando do atendimento a alguém $\mathrm{HIV+}$, mas que geralmente isso não acontece. "O Sistema de Informação de Agravos de Notificação - Sinan é alimentado, principalmente, pela notificação e investigação de casos de doenças e agravos que constam da lista nacional de doenças de notificação compulsória" (BRASIL, 2017a, s.p.). Não existe na portaria que regulamenta o SINAN, nem no portal específico que a função de notificar seria de um profissional específico.

Pode-se inferir que como a enfermeira é a responsável por algumas atividades administrativas na unidade de saúde, acabe assumindo mais essa responsabilidade para efetivar o processo de notificação, inclusive porque geralmente encontra-se na unidade diariamente.

Outro profissional citado nas falas que atua na equipe foi o farmacêutico, que trabalha na farmácia da unidade especializada e tem um contato direto na distribuição das medicações prescritas para a gestante, esclarecendo as dúvidas sobre o uso e estimulando a continuidade do tratamento. $O$ profissional farmacêutico é aquele que tem por uma de suas responsabilidades definida pela Lei do Exercício Profissional (BRASIL, 2014), acompanhar os pacientes em unidades ambulatoriais na perspectiva farmacoterapêutica, o que acontece no SAE, que atende ambulatorialmente as gestantes HIV +.

Ainda em relação à equipe multiprofissional, foram citados pelos entrevistados os profissionais de assistência social, que atuam na assistência à gestante com HIV+ direcionando os encaminhamentos para laqueadura tubária e outras questões de cunho social. Percebeu-se que o assistente social na equipe multiprofissional desempenha um papel importante na orientação e condução para o alcance dos direitos e benefícios sociais, articulando com os programas e serviços sociais, na busca pela garantia destes para os pacientes com HIV+.

Já em relação ao atendimento do odontólogo à gestante HIV +, foi possível identificar o encaminhamento da mulher por algum dos profissionais já mencionados, principalmente o médico e a atuação incluem procedimentos comuns da área de Odontologia para qualquer usuário do serviço de saúde.

O psicólogo na equipe multiprofissional atua com as gestantes HIV+, nem sempre com demandas psicológicas relacionadas à descoberta ou vivência como vírus. Foi possível perceber pelas entrevistas que a gestante traz consigo uma série de demandas emocionais que precisam ser ajustadas para seguimento das atividades habituais da vida cotidiana. A existência de demandas da família, as dificuldades financeiras, o estigma de possuir o vírus HIV; o receio de transmitir para outras pessoas, pautado no pouco conhecimento a respeito, tudo isso associado às mudanças hormonais, físicas e psicológicas que a própria gestação causa, leva a gestante à necessidade de suporte e acompanhamento com o psicólogo.

A equipe multiprofissional ainda contempla os técnicos de Enfermagem, responsáveis de acordo com a pesquisa, pela recepção inicial da gestante no serviço de pré-natal. Segundo a Lei do Exercício profissional de $\mathrm{n}^{\circ} 7.498$ de 1986 que regulamenta a atuação da Enfermagem, no art. 15 determina que as atividades do técnico de enfermagem só podem ser realizadas sob a supervisão da Enfermeira (BRASIL, 1986).

Observou-se que as atividades técnicas que são delegadas aos técnicos de enfermagem nas consultas de pré-natal, que consistem em medidas antropométricas, sinais vitais. No entanto, estas também realizam outras atividades como: entrevista e avaliação dos cartões de vacina, as quais podem ser feitas por eles numa perspectiva mais simples, visto que a Consulta de Enfermagem com análise mais aprofundada do histórico da gestante, a elaboração 
de diagnósticos e prescrição de Enfermagem são ações privativas do enfermeiro (BRASIL, 2017b).

Já os técnicos de laboratório integraram a equipe, atuando no cadastro/acolhimento inicial e coleta de amostras biológicas para exames laboratoriais. Porém, foi possível identificar que há diálogo entre a técnica de laboratório e a usuárias no sentido destas últimas perceberem a obrigação de fazerem o acompanhamento. O diálogo enquanto se coleta exames de laboratório pode contribuir para o relaxamento da pessoa antes da retirada do sangue, mas não se pode ultrapassar a especificidade das atribuições profissionais.

\section{CONSIDERAÇÕES FINAIS}

O estudo alcançou o objetivo proposto visto que foi possível compreender a atuação dos profissionais de saúde na assistência às gestantes HIV+ no Centro de Referência DST-HIVAIDS de Feira de Santana - BA e a partir desse objetivo refletir as práticas de cuidado.

No que se refere à atuação multidisciplinar, cada profissional desempenha papel singular e relevante em suas atividades, e mencionaram uns aos outros como atores no processo interdisciplinar de resolução das demandas apresentadas pelas gestantes HIV+, ressaltando que ocorre um trabalho em equipe com a valorização de cada área de conhecimento. A assistência realizada à gestante com HIV+ pela equipe multiprofissional mostrou um grau de compromisso social dos participantes com a população feminina atendida e com sua família.

\section{REFERÊNCIAS}

BARROS, L. A. et al. Soropositividade de HIV em gestantes: adequação das práticas e atividades desenvolvidas pelo Serviço de Assistência Especializada. Cadernos de Graduação - Ciências Biológicas e da Saúde Fits, Maceió, v. 1, n.1, p. 67-82, nov. 2012. Disponível em: <https://periodicos.set.edu.br/index.php/fitsbiosaude/article/view/458>. Acesso em 09/03/2017.

BRASIL. COFEN. Lei no 7. 498/86, de junho de 1986. Brasília, 1986. Disponível: < http://www.cofen. gov.br/lei-n-749886-de-25-de-junho-de-1986_4161.html>. Acesso em: 28 ago. 2018.

BRASIL. CONSELHO FEDERAL DE FARMÁCIA. Resolução no 596 de 21 de fevereiro de 2014. Brasília, 2014. Disponível em: <http://www.cff.org.br/userfiles/file/ resolucoes/596.pdf>. Acesso em: 27 ago. 2018.

BRASIL. Ministério da Saúde. Secretaria de Vigilância em Saúde - Departamento de DST, Aids e Hepatites Virais. Indicadores e dados básicos da Aids do município de Feira de Santana- BA. 2016. Disponível em: <http://indicadores.aids.gov.br/>. Acesso em 09 abr. 2017.

BRASIL. SINAN. Funcionamento. Brasília, 2017a. Disponível em: <http://portalsinan.saude.gov.br/funcionamentos〉. Acesso em: 29 de ago. 2018.

BRASIL. COFEN. Resolução COFEN no 564/2017 - Aprova o novo Código de Ética dos Profissionais de Enfermagem. Brasília, 2017b. Disponível em: < http://www.cofen.gov.br/resolucao-cofen-no-5642017_59145.html>. Acesso em: 29 de ago. 2018. 